Supporting Information

\title{
Tuning Organic Microcrystal Morphologies through Crystal Engineering Strategies toward Anisotropic Optical Waveguide
}

Zeyang Ding, Hongxing Shang, Yijia Geng, Shi-Tong Zhang, Zepeng Huo, Zairan

Yang, Bao Li, Weiqing Xu and Shimei Jiang*

E-mail: $\underline{\text { smjiang@jlu.edu.cn }}$ 


\section{Contents}

Materials and methods......................................................... 3

Crystal growth, Theoretical and Computational Method........................S4

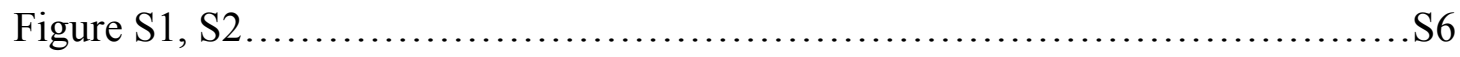

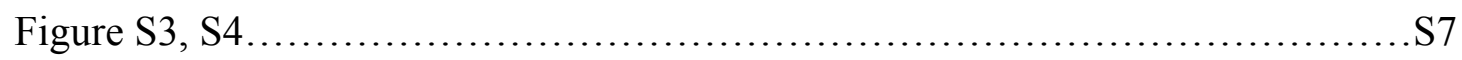

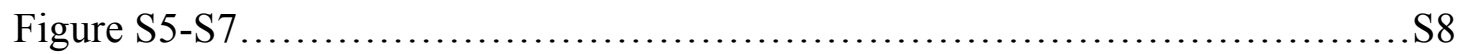

$\begin{array}{lllll}\mathrm{T} & \mathrm{a} & \mathrm{b} & 1 & \mathrm{e}\end{array}$

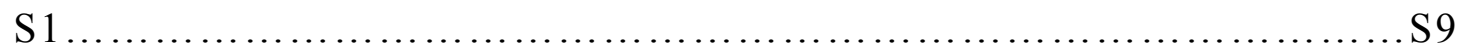

Figure S8, S9, Table S2 ........................................... 10

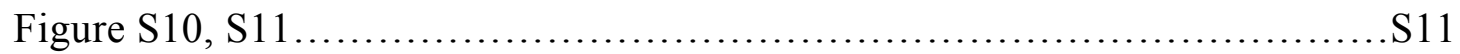

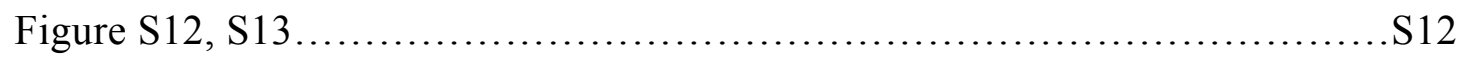

Figure S14, S15, Table S3 ......................................... 13

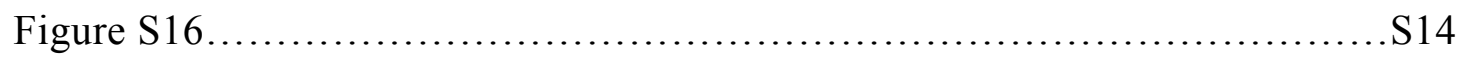




\section{Materials and methods}

$\mathrm{CF}_{3}$-CN-Py powder was synthesized according to a reported procedure (Figure $\mathrm{S} 1$ ) and its ${ }^{1} \mathrm{H},{ }^{13} \mathrm{C}$ NMR and Mass spectra were listed in Figure S2-S4. 1,4diiodotetrafluorobenzene (FDIB) was purchased from commercial sources and used directly without further purification unless otherwise stated. ${ }^{1} \mathrm{H}$ and ${ }^{13} \mathrm{C}$ NMR spectra were recorded on a Bruker AVANCE $400 \mathrm{MHz}$ spectrometer (TMS as the internal standard). Mass spectrum (MS) was collected on a Thermo Scientific ITQ $1100^{\mathrm{TM}}$ GC/MS. Fluorescence spectra of solution were scanned with a Shimadzu RF-5301PC spectrophotometer. Fluorescence spectra of solid were recorded using a Maya2000 Pro CCD spectrometer. Quantum efficiency were carried out with Edinburgh fluorescence spectrometer (FLS920). FT-IR spectra were recorded on a Bruker Optics VERTEX 80v Fourier transform infrared spectrometer, equipped with a DTGS detector in pressed $\mathrm{KBr}$ pellets. Differential scanning calorimetry (DSC) measurements were collected on a Netzsch DSC 204 at a $10{ }^{\circ} \mathrm{C} / \mathrm{min}$ scanning rate under nitrogen. Thermal gravimetric analyzer (TGA) measurements were scanned on a TA Q500 at a $10{ }^{\circ} \mathrm{C} / \mathrm{min}$ scanning rate under nitrogen. X-ray diffraction (XRD) patterns were obtained with a Rigaku D/MAX 2500/PC X-ray diffractometer. The fluorescence microscopy images were obtained from an Olympus BX51 fluorescence microscope (the excitation wavelength was 330-385 nm). Scanning electron microscopy (SEM) images were collected with a JEOL JEM-6700F at $3 \mathrm{kV}$, with the samples coated with Au. Transmission electron microscopy (TEM) was performed with a JEOL JEM-2100F transmission electron 
microscope. Single-crystal X-ray diffraction data were collected on a Rigaku R-AXIS RAPID diffractometer using the $\omega$-scan mode with graphite monochromator Mo Ka radiation. The structure determination was solved with direct methods using SHELXTL and refined with full-matrix least-squares on $F^{2}$. Non-hydrogen atoms were refined anisotropically. The positions of hydrogen atoms were calculated and refined isotropically.

\section{Crystal growth}

2D plate crystal: $12.4 \mathrm{mg} \mathrm{CF}$ - $\mathrm{CN}-\mathrm{Py}$ was dissolved in $2 \mathrm{~mL}$ chloroform, which was then placed in a vial with unscrewed cap. Achromatous plate crystals were obtained within one week at room temperature.

3D micro-helix: Chloroform containing $\mathrm{CF}_{3}-\mathrm{CN}-\mathrm{Py}(1 \mathrm{mg} / \mathrm{mL})$ was dropped on the surface of quartz/silicon plate. The quartz/silicon plate was then placed into a sealed weighing bottle with a supported copper table and ethanol (poor solvent) was around the copper table. After 6 hours solvent diffusion at room temperature, helix and wire microcrystals were obtained. It is noticed that the helixes and wires appeared together (part of wires exhibited helix feature).

1D co-crystal: Equimolar quantities of $\mathrm{CF}_{3}-\mathrm{CN}-\mathrm{Py}(9.9 \mathrm{mg})$ and FDIB (4.0 mg) were dissolved in $2 \mathrm{~mL}$ DCE, which was then placed in a vial with unscrewed cap. Faint yellow rod co-crystals were attained within one week at room temperature.

\section{Theoretical and Computational Method}

The transition dipole moments $(\mu)$ were computed based on the molecular skeleton selected from the crystal and co-crystal in corresponding unit cells. C, N, O, F atoms 
were calculated at the td-m062x/6-31g(d,p) level. I atom was calculated at the tdm062x/lanl2dz level. All the calculations were carried out using the Gaussian 09 package. The growth morphology of crystal and co-crystal were simulated by Materials Studio software.

CCDC 1430653 and 1430719 contain the supplementary crystallographic data for this paper. These data can be obtained free of charge from The Cambridge Crystallographic Data Centre via www.ccdc.cam.ac.uk/data_request/cif.] 

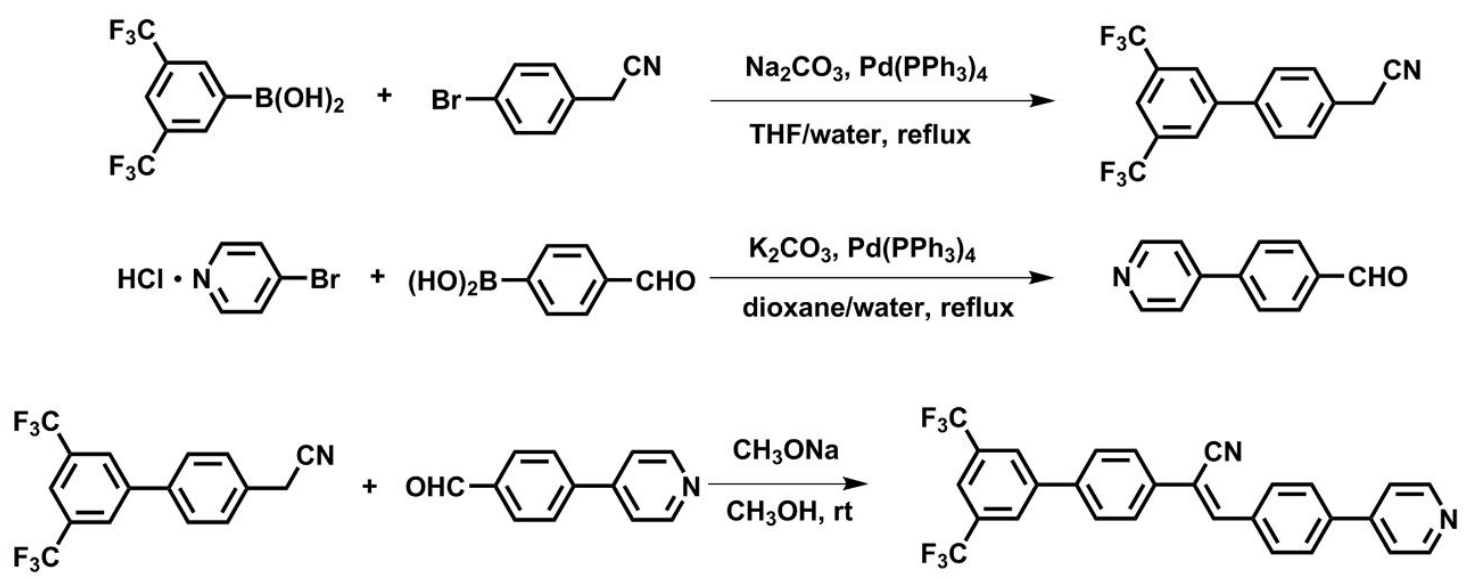

Figure S1. Detailed synthetic routes of $\mathrm{CF}_{3}-\mathrm{CN}-\mathrm{Py}$.

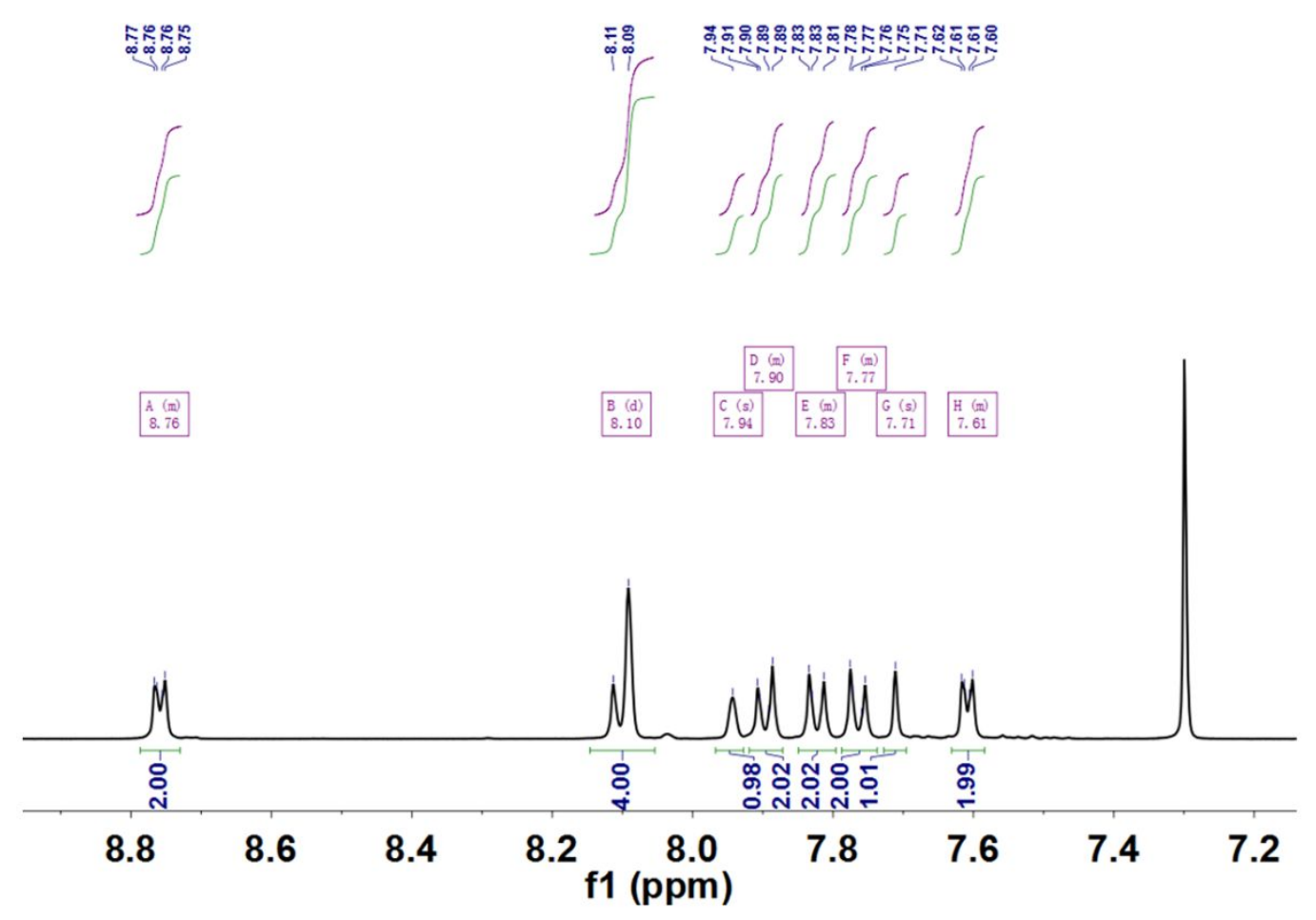

Figure S2. ${ }^{1} \mathrm{H} \mathrm{NMR}(400 \mathrm{MHz})$ spectrum of $\mathrm{CF}_{3}-\mathrm{CN}-\mathrm{Py}$ in $\mathrm{CDCl}_{3}$. 

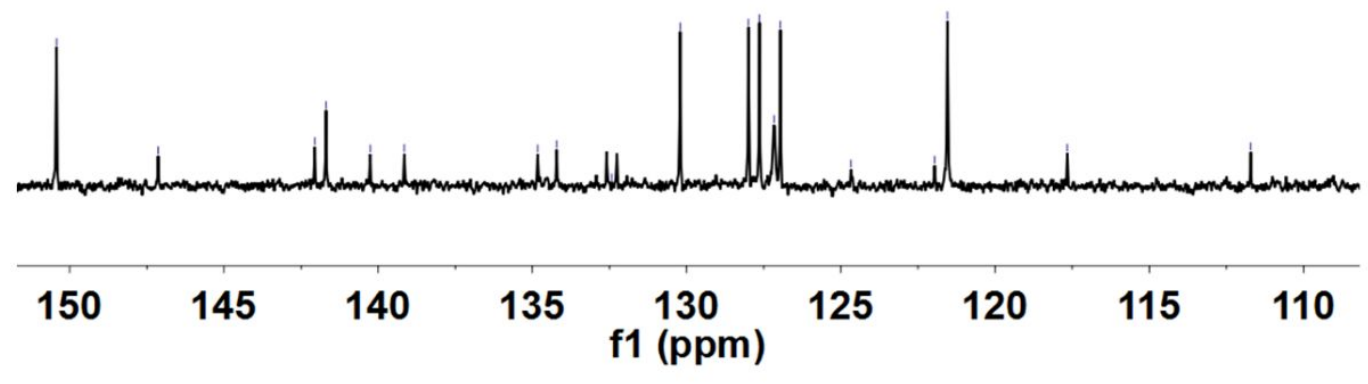

Figure S3. ${ }^{13} \mathrm{C}$ NMR (400 MHz) spectrum of $\mathrm{CF}_{3}-\mathrm{CN}-\mathrm{Py}$ in $\mathrm{CDCl}_{3}$.

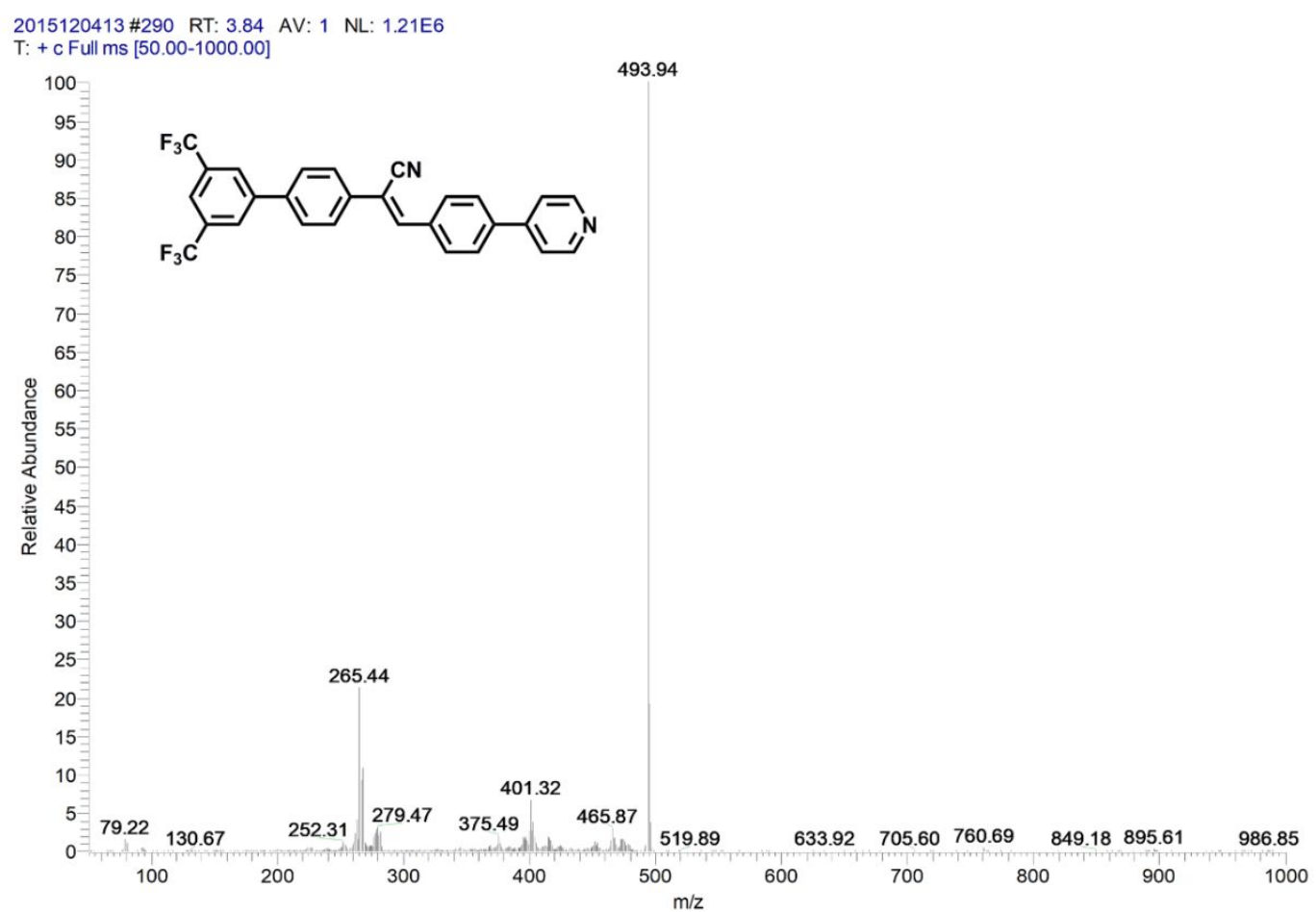

Figure S4. Mass spectrum of $\mathrm{CF}_{3}-\mathrm{CN}-\mathrm{Py}$. 
a)

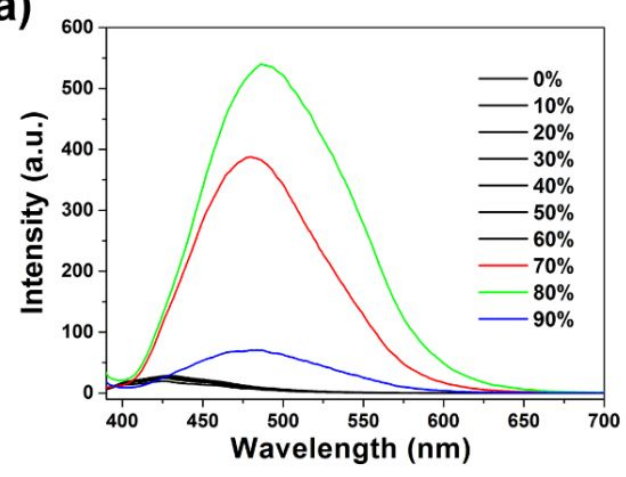

b)

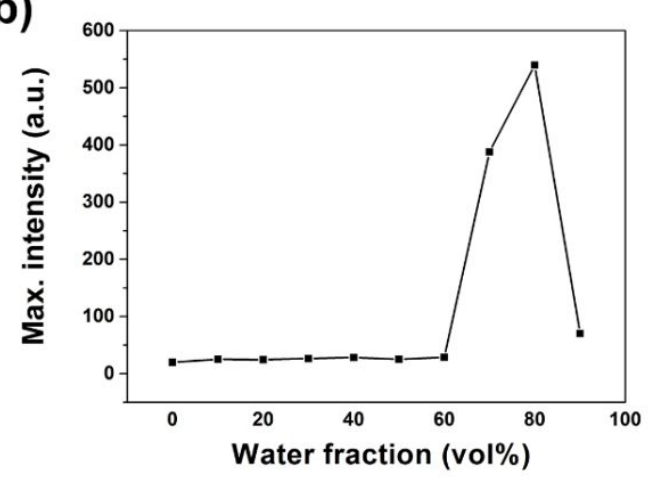

Figure S5. (a) Fluorescence spectra of $\mathrm{CF}_{3}-\mathrm{CN}-\mathrm{Py}$ in THF/water mixtures $(20 \mu \mathrm{M})$ with different water volume fractions (from 0 to $90 \%, \lambda_{\mathrm{ex}}=365 \mathrm{~nm}$ ). (b) Plots of maximal intensity versus the water fractions.
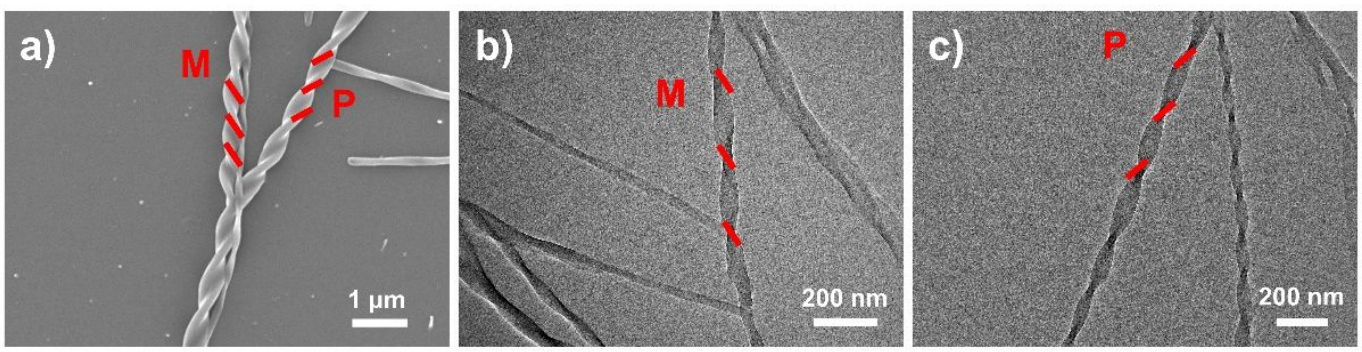

Figure S6. Left-handed helix (M) and right-handed one (P) in one batch.

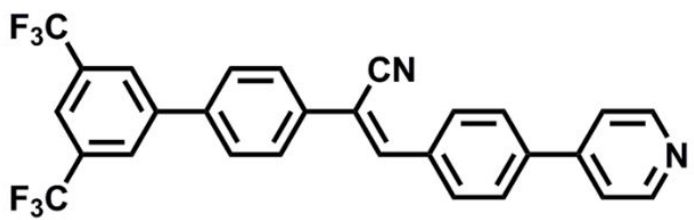

\section{Ar1 Ar2 Ar3 Ar4}

\begin{tabular}{llll}
\hline & $\angle($ Ar1-Ar2 $)$ & $\angle($ Ar2-Ar3 $)$ & $\angle($ Ar3-Ar4 $)$ \\
\hline plate crystal & $28.4^{\circ}$ & $35.1^{\circ}$ & $34.9^{\circ}$ \\
co-crystal & $2.1^{\circ}$ & $4.3^{\circ}$ & $30.4^{\circ}$ \\
\hline
\end{tabular}

Figure S7. Angle parameters of $\mathrm{CF}_{3}-\mathrm{CN}$-Py molecule in plate crystal and co-crystal. 
Table S1. Details of crystallographic data for crystal and co-crystal.

\begin{tabular}{|c|c|c|}
\hline & Plate crystal & Co-crystal \\
\hline Empirical formula & C28 H16 F6 N2 & C62 H32 F16 I2 N4 \\
\hline Formula weight & 494.43 & 1390.72 \\
\hline Temperature & 293(2) K & 293(2) K \\
\hline Wavelength & $0.71073 \mathrm{~A}$ & $0.71073 \mathrm{~A}$ \\
\hline Crystal system, space group & Monoclinic, P 21/c & Triclinic, $\mathrm{P}-1$ \\
\hline Unit cell dimensions & $\begin{array}{l}\mathrm{a}=14.799(3) \AA \quad \alpha=90^{\circ} \\
\mathrm{b}=9.962(2) \AA \quad \beta=90.54(3)^{\circ} \\
\mathrm{c}=15.092(3) \AA \quad \gamma=90^{\circ}\end{array}$ & $\begin{array}{ll}a=4.8893(10) \AA & \alpha=67.58(3)^{\circ} \\
b=15.372(3) \AA & \beta=89.54(3)^{\circ} \\
c=19.518(4) \AA & \gamma=87.55(3)^{\circ}\end{array}$ \\
\hline Volume & $2224.8(8) \AA^{3}$ & $1354.8(5) \AA^{3}$ \\
\hline Z, Calculated density & $4,1.476 \mathrm{Mg} \mathrm{m}^{-3}$ & $1,1.705 \mathrm{Mg} \mathrm{m}^{-3}$ \\
\hline Absorption coefficient & $0.122 \mathrm{~mm}^{-1}$ & $1.262 \mathrm{~mm}^{-1}$ \\
\hline $\mathrm{F}(000)$ & 1008 & 682 \\
\hline Crystal size & $0.13 \times 0.12 \times 0.10 \mathrm{~mm}$ & $0.13 \times 0.12 \times 0.10 \mathrm{~mm}$ \\
\hline Theta range for data collection & $3.02-27.43^{\circ}$ & $3.10-27.48^{\circ}$ \\
\hline Limiting indices & $\begin{array}{l}-19<=\mathrm{h}<=19,-12<=\mathrm{k}<=12, \\
-19<=\mathrm{l}<=19\end{array}$ & $\begin{array}{l}-5<=\mathrm{h}<=6,-19<=\mathrm{k}<=19, \\
-25<=1<=25\end{array}$ \\
\hline Reflections collected/unique & $20700 / 5059[\mathrm{R}(\mathrm{int})=0.0240]$ & $12840 / 6004[\mathrm{R}(\mathrm{int})=0.0256]$ \\
\hline Completeness to theta $=27.43$ & $99.6 \%$ & $96.4 \%$ \\
\hline Absorption correction & Semi-empirical from equivalents & Semi-empirical from equivalents \\
\hline Max. and min. transmission & 0.9879 and 0.9843 & 0.8842 and 0.8531 \\
\hline Refinement method & Full-matrix least-squares on $\mathrm{F}^{2}$ & Full-matrix least-squares on $\mathrm{F}^{2}$ \\
\hline Data/restraints/parameters & $5059 / 0 / 325$ & $6004 / 96 / 434$ \\
\hline Goodness-of-fit on $\mathrm{F}^{2}$ & 1.092 & 1.090 \\
\hline Final $R$ indices $[\mathrm{I}>2 \operatorname{sigma}(\mathrm{I})]$ & $\mathrm{R} 1=0.0553, \mathrm{wR} 2=0.1638$ & $\mathrm{R} 1=0.0467, w \mathrm{R} 2=0.1426$ \\
\hline $\mathrm{R}$ indices (all data) & $\mathrm{R} 1=0.0680, \mathrm{wR} 2=0.1737$ & $\mathrm{R} 1=0.0584, \mathrm{wR} 2=0.1474$ \\
\hline
\end{tabular}


a)

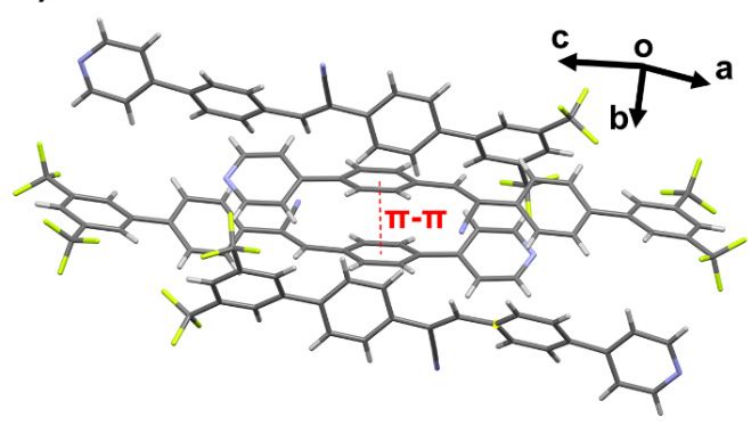

b)

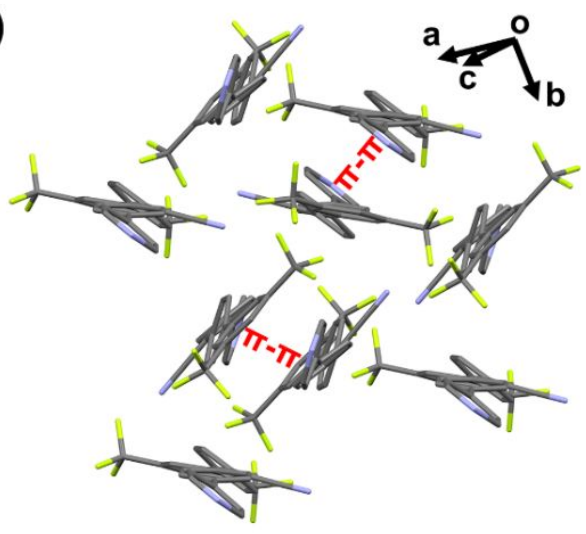

Figure S8. $\pi-\pi$ interactions of $\mathrm{CF}_{3}-\mathrm{CN}-\mathrm{Py}$ in plate crystal.

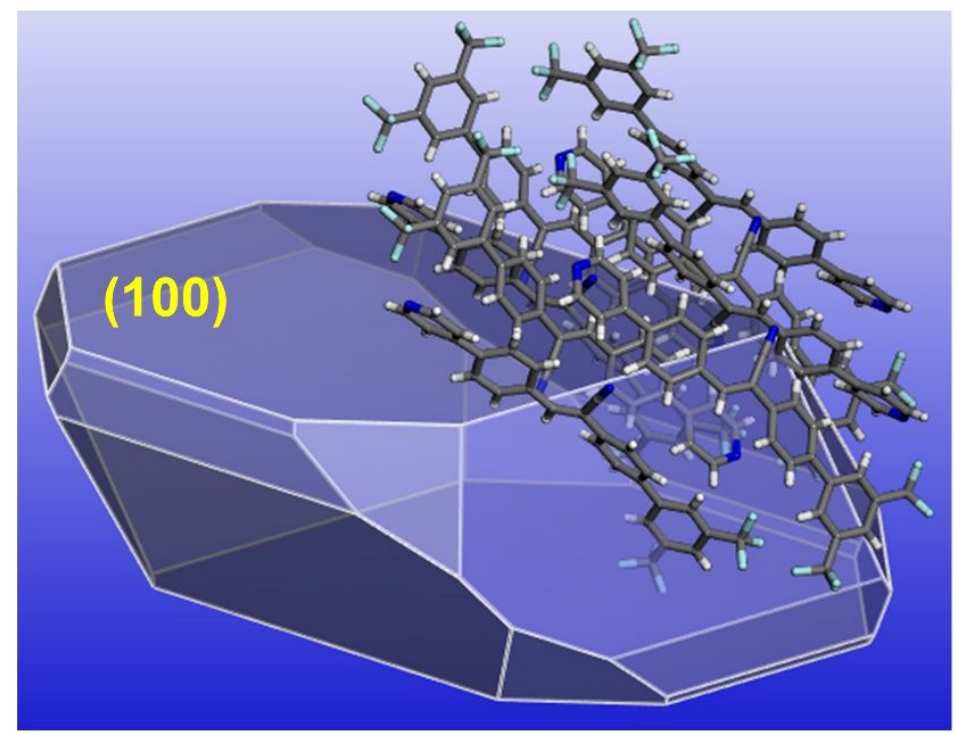

Figure S9. The predicted growth morphology of plate crystal.

Table S2. The calculated attachment energy for different crystal faces of plate crystal.

\begin{tabular}{l|ll} 
Miller Index & Eatt (total) $(\mathbf{k c a l} / \mathbf{m o l})$ & Total facet area \\
\hline$(100)$ & -58.49 & $39.29 \%$ \\
$(111)$ & -87.26 & $39.71 \%$ \\
$(110)$ & -105.46 & $5.60 \%$
\end{tabular}



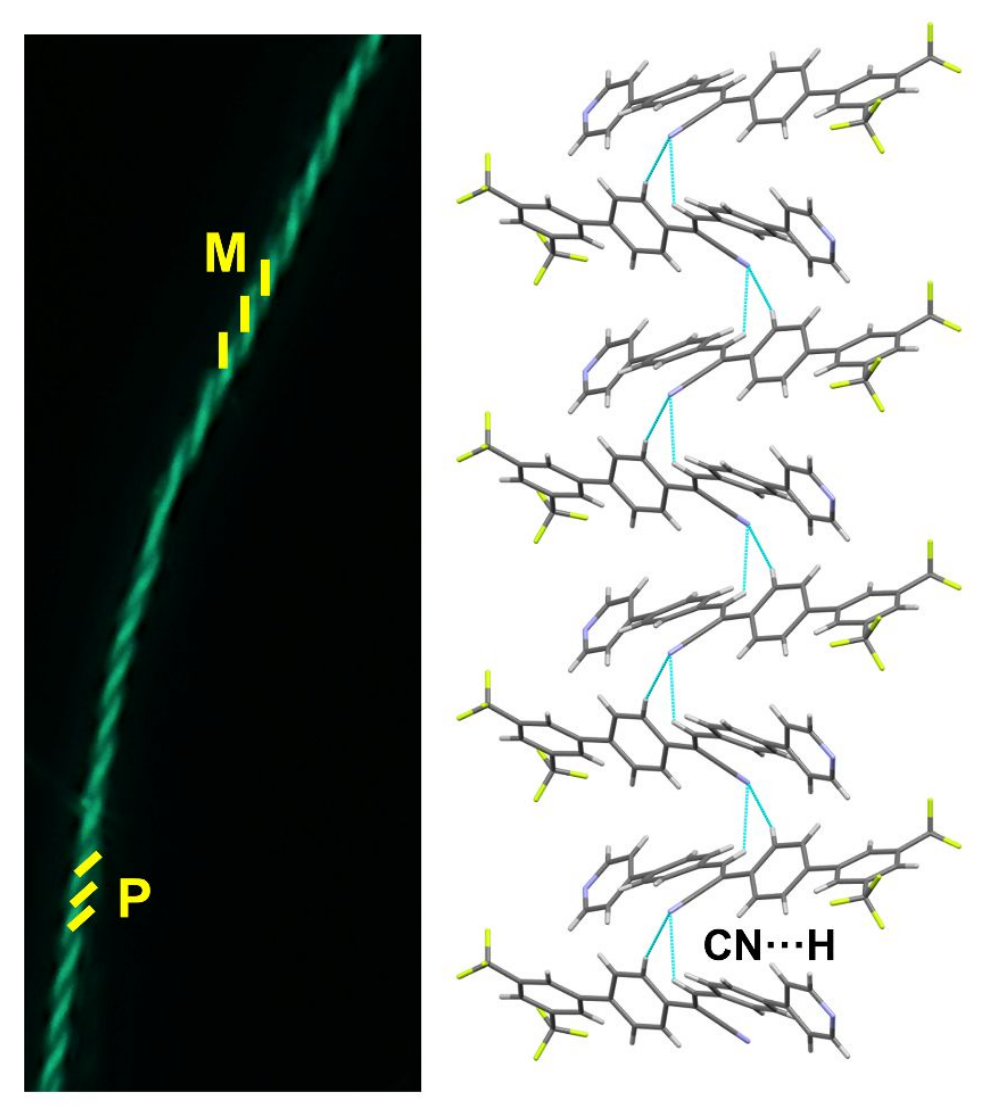

Figure S10. Proposed molecular packing in micro-helix.

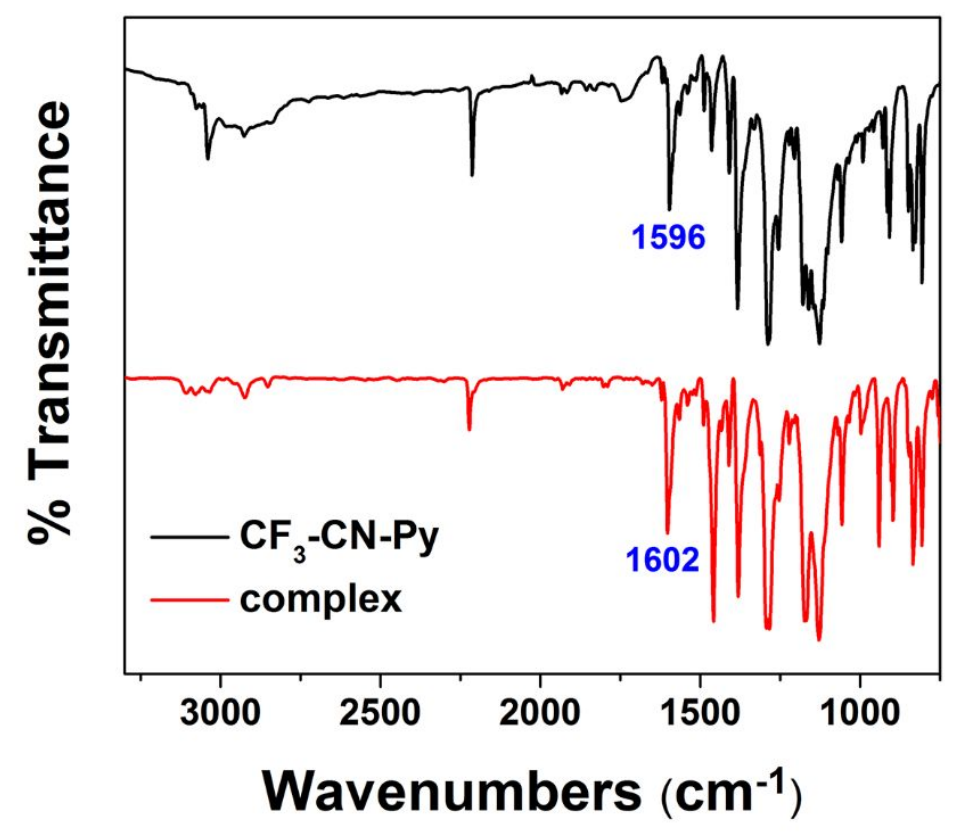

Figure S11. FT-IR spectra of complex and its precursor $\left(\mathrm{CF}_{3}-\mathrm{CN}-\mathrm{Py}\right)$. 
a)

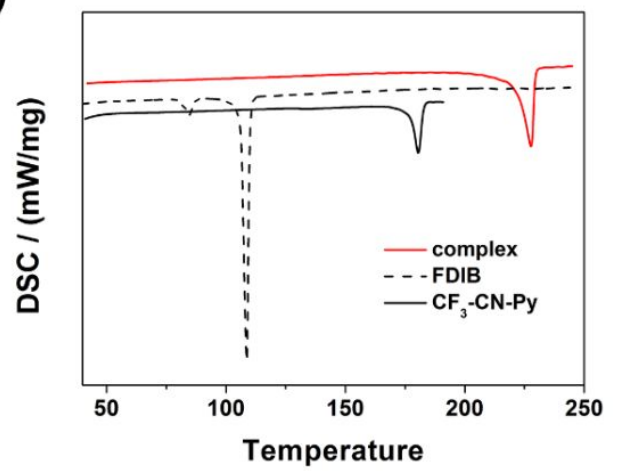

b)

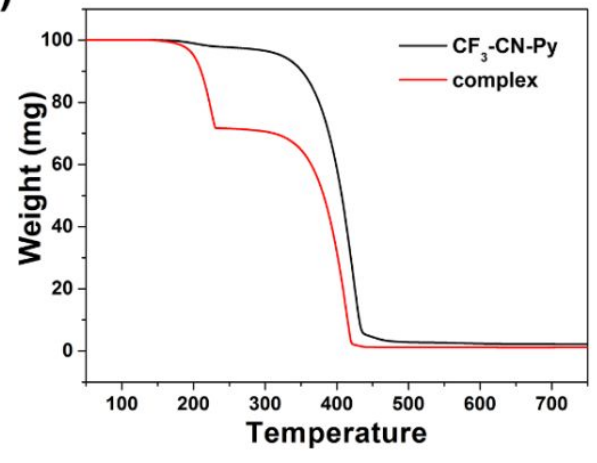

Figure S12. (a) DSC and (b) TGA profiles of complex and its precursor.

a)

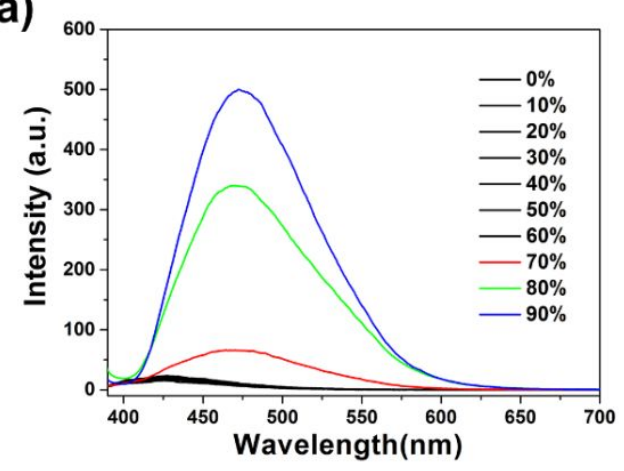

b)

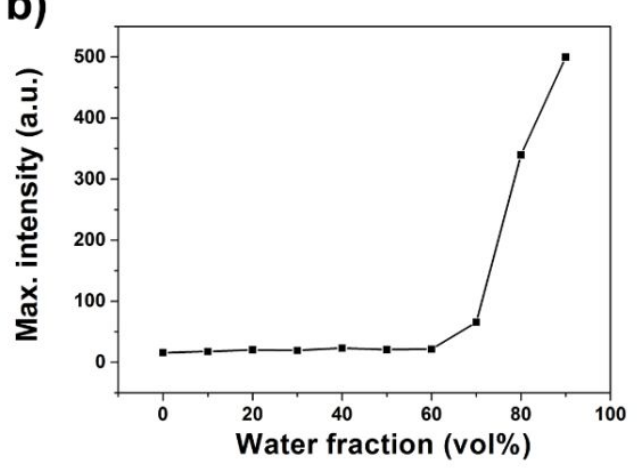

Figure S13. (a) Fluorescence spectra of complex in THF/water mixtures $(20 \mu \mathrm{M})$ with different water volume fractions (from 0 to $90 \%, \lambda_{\mathrm{ex}}=365 \mathrm{~nm}$ ). (b) Plots of maximal intensity versus the water fractions. 


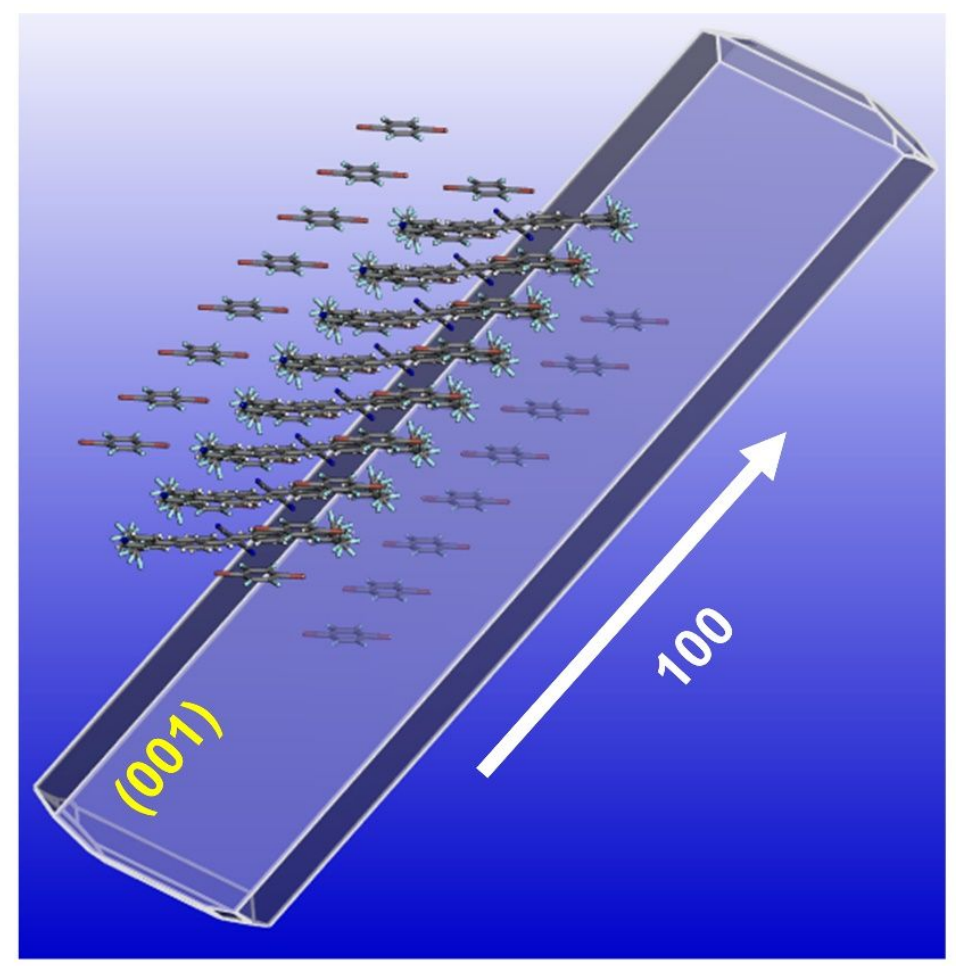

Figure S14. The predicted growth morphology of co-crystal.

Table S3. The calculated attachment energy for different crystal faces of co-crystal.

\begin{tabular}{l|ll} 
Miller Index & Eatt (total) (kcal/mol) & Total facet area \\
\hline$(001)$ & -17.85 & $47.86 \%$ \\
$(011)$ & -26.13 & $23.61 \%$ \\
$(010)$ & -27.84 & $18.97 \%$
\end{tabular}
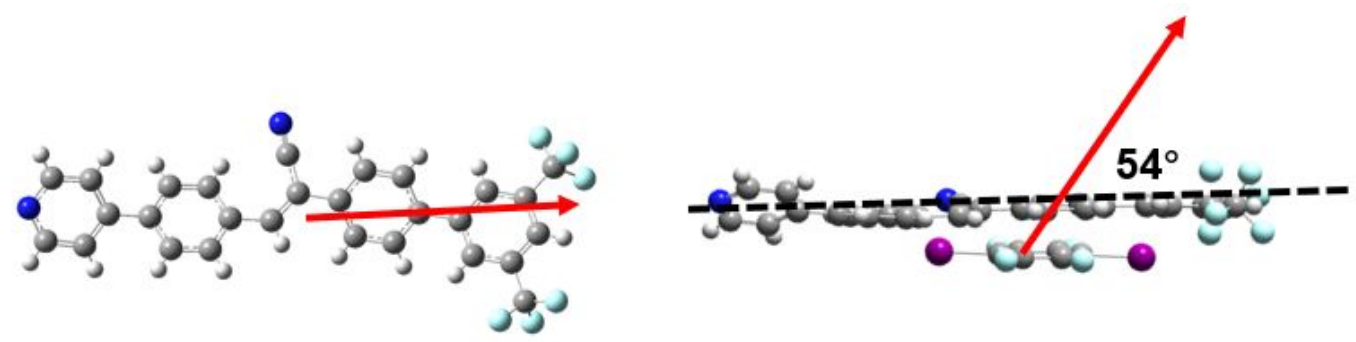

Figure S15. Calculated transition dipole moment in plate crystal (left) and co-crystal (right). 


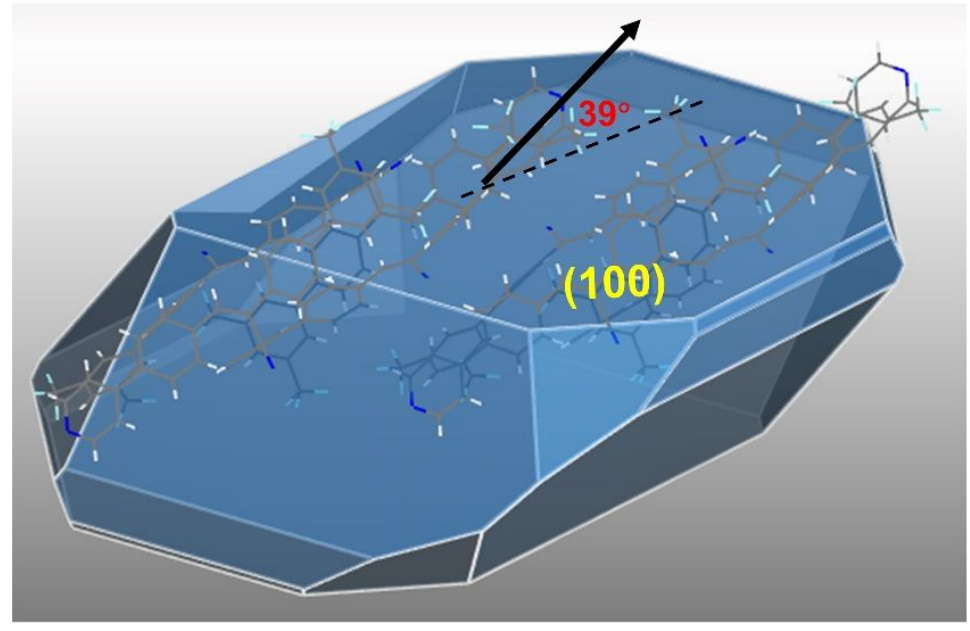

Figure S16. Transition dipole orientations (black arrow) and the angle between transition dipole orientations and the upper surface ((100) crystal face) in 2D plate crystal. 